\title{
Os controles políticos sobre a burocracia*
}

\author{
Cecília Olivieri**
}

Sumário: 1. Democracia, governo e burocracia em Max Weber; 2. A relação entre política e burocracia no Brasil e nos EUA; 3. O controle dos políticos sobre a burocracia.

Summary: 1. Democracy, government and bureaucracy in Max Weber; 2 . The relationship between politics and bureaucracy in Brazil and the U.S; 3. The control of politicians over the bureaucracy.

Palavras-chave: burocracia; controles democráticos; controle político da burocracia.

KEY WORDs: bureaucracy; democratic controls; political control over bureaucracy.

O artigo revisa a literatura sobre os temas da relação entre política e burocracia e dos controles democráticos sobre a burocracia analisando três conjuntos de obras: a produção weberiana sobre a relação entre governo e burocracia, a literatura norteamericana e a produção nacional. A obra weberiana nos permite estabelecer com precisão as características centrais da burocracia moderna, seu papel no governo democrático contemporâneo e a necessidade do controle dos políticos sobre a burocracia. O debate norte-americano, por sua vez, explicita a ausência, no Brasil, de discussão sobre a relação entre política e burocracia na perspectiva democrática. A despeito desta ausência, analisamos a literatura nacional contemporânea com o objetivo de traçar um panorama da situação dos controles sobre a burocracia no Brasil e compreender, ainda que de forma incipiente, como funcionam os mecanismos de controle, em especial a nomeação, o orçamento, a legislação e o monitoramento.

Political controls over the bureaucracy

The article reviews the literature on the themes of the relationship between politics and bureaucracy and democratic control over the bureaucracy by analyzing three

* Artigo recebido em set. 2010 e aceito em mar. 2011.

** Professora doutora da Escola de Artes, Ciências e Humanidades (EACH) da Universidade de São Paulo (USP). Endereço: rua Arlindo Béttio, 1000 — Ermelino Matarazzo — CEP 03828-000, São Paulo, SP, Brasil. Email: cecilia.olivieri@usp.br. 
sets of works: Weber's production on the relationship between government and bureaucracy, the North American literature and national production. Weber's work allows us to establish with precision the central features of modern bureaucracy, its role in contemporary democratic government and the need for political control over bureaucracy. The debate in the U.S., in turn, explains the absence, in Brazil, the discussion on the relationship between politics and bureaucracy in a democratic perspective. Despite this absence, we analyze the contemporary literature in order to describe the present situation of the controls on the bureaucracy in Brazil and understand, even in incipient way, the mechanics of control, in particular the appointment, the budget, legislation and monitoring.

Os temas da relação entre política e burocracia e dos controles democráticos sobre a burocracia têm sido praticamente negligenciados pela literatura nacional, a despeito de sua importância para a compreensão de questões atuais como qualidade e eficiência da gestão pública, responsabilização dos governantes perante a sociedade e democratização do Estado. A burocracia não é apenas o conjunto dos funcionários públicos e dos processos administrativos, mas um dos fundamentos do exercício do poder estatal e do governo democrático, e por isso é necessária a compreensão sobre sua composição, seu funcionamento e sua relação com os dirigentes políticos eleitos.

Para discutir estes temas, o artigo revisa a literatura com foco em três conjuntos de obras: a produção weberiana sobre a relação entre governo e burocracia, a literatura norte-americana e a produção nacional. Nossa leitura foi guiada pelo objetivo de chegar à discussão, na última sessão, do estado dos controles políticos sobre a burocracia no Brasil contemporâneo. Apesar de, como já dissemos, a literatura nacional não tratar dos controles políticos sobre a burocracia, cremos que seja possível indicar os motivos dessa lacuna e os caminhos para preenchê-la - e para este trabalho a análise da produção norte-americana é fundamental, já que nossos sistemas políticos são institucionalmente semelhantes, e esse tema é desenvolvido de forma aprofundada em muitas obras. A obra weberiana, por sua vez, nos permite estabelecer com precisão as características centrais da burocracia moderna, seu papel no governo democrático contemporâneo e a necessidade do controle dos políticos sobre a burocracia. Este é o conteúdo da primeira seção do artigo.

A seção seguinte prossegue com a comparação entre Brasil e EUA quanto ao tratamento teórico do tema da relação entre política e burocracia e ao dos controles sobre a burocracia, e nos permite apontar com mais clareza os termos desse debate entre nós ou, na verdade, por que a discussão sobre burocracia no Brasil não inclui a preocupação com a democracia e com 
o controle político sobre a burocracia. O debate norte-americano explicita a ausência, no Brasil, de discussão sobre a relação entre política e burocracia na perspectiva democrática. O olhar dos cientistas sociais brasileiros sobre a burocracia sempre teve como foco a construção do Estado, e não as condições de democratização da administração pública e de responsabilização dos dirigentes políticos. Consequentemente, o debate acerca do controle político sobre a burocracia é praticamente inexistente no Brasil, especialmente se comparado à profusão de textos sobre o tema nos EUA. As semelhanças institucionais entre os dois países - presidencialismo, burocracia aberta a entrada lateral e a nomeações políticas, tradição clientelista (spoils system) — não produziram preocupações teóricas semelhantes a respeito do controle democrático sobre a burocracia.

Essa breve comparação mostra, ainda, que o espelho americano não pode ser aproveitado em sua totalidade, devido às particularidades da distribuição de poder entre os Poderes Executivo e Legislativo no Brasil em relação aos EUA. Uma diferença fundamental entre os dois países - a predominância do Poder Executivo nas relações com o Legislativo no Brasil, em face do equilíbrio das relações entre os dois Poderes nos EUA - explica a aparência do tema do controle político sobre a burocracia no Brasil como uma ideia "fora de lugar" e explica, também, parcela do desinteresse da literatura nacional pela questão. Essa aparência, entretanto, é falsa, e o desinteresse, improdutivo.

Finalmente, a terceira seção revisa a literatura contemporânea com o objetivo de traçar um panorama da situação dos controles sobre a burocracia no Brasil. As obras citadas, com exceção do trabalho sobre o controle interno, não problematizam analiticamente a questão do controle sobre a burocracia, mas trazem contribuições que nos permitem compreender, ainda que de forma incipiente, como funcionam os mecanismos de controle, em especial a nomeação, o orçamento, a legislação e o monitoramento.

\section{Democracia, governo e burocracia em Max Weber}

As questões desenvolvidas por Weber sobre burocracia e governo ainda são atuais, e dois temas centrais no seu pensamento são particularmente contemporâneos e importantes para o estudo do controle político da burocracia, balizando nossa leitura de seus textos:

v A expansão da burocracia nos domínios público e privado, devido à sua superioridade técnica. 
- O conflito latente entre burocratização e democratização, expresso, entre outras formas, nas disputas sobre o controle da burocracia em nome da democracia.

A burocracia continua um objeto importante de estudo em função não apenas de sua presença crescente, mas também por causa das implicações de seu funcionamento para a democracia. Enquanto forma de organização do domínio, a burocracia continua em expansão nas sociedades contemporâneas, apesar dos movimentos de reforma administrativa por que muitos países passaram na década de 1980 e do enorme desenvolvimento da tecnologia da informação. As reformas administrativas tinham como um de seus objetivos reduzir o tamanho da burocracia, enquanto a revolução da informática trazia a possibilidade da extinção de processos e papelórios e, portanto, também de redução de procedimentos burocráticos e até da quantidade de funcionários. Entretanto, o que se observa é que as reformas não reduziram o tamanho dos aparatos administrativos (Pollitt e Bouckaert, 2002) e a tecnologia da informação, apesar de possibilitar a redução dos processos, também levou à criação de novas atividades e de novas demandas ao Estado (Medeiros e Guimarães, 2004).

As implicações do desenvolvimento da burocracia para o governo democrático também continuam atuais, uma vez que a democracia, apesar de todas as mudanças que ocorreram nas últimas décadas, continua dependendo da expansão da burocracia na medida em que o aparato burocrático é o responsável pela garantia das regras legais que sustentam o sistema político. Entretanto, o desenvolvimento da burocracia pode representar uma ameaça à democracia, pois os burocratas podem usurpar dos políticos o poder de decidir sobre os assuntos do governo. Essa questão do controle democrático sobre os atos do governo tem aparecido atualmente na literatura das ciências sociais, em especial da ciência política, sob o conceito de accountability, ou seja, a capacidade do governo e da sociedade de controlarem as decisões tomadas por políticos e burocratas.

Neste trabalho, utilizaremos a seguinte definição de accountability política: relação formal entre um ator que pode legalmente controlar, monitorar e/ou punir um agente público (Mainwaring e Welna, 2003). A accountability política é, portanto, uma relação entre um ator ou órgão de controle e um agente público (seja político ou burocrata). Essa relação se caracteriza pela obrigação legal do agente público de responder ao ator ou órgão de controle. Segundo Mainwaring, essa relação não inclui, necessariamente, a capacidade de sanção pelo ator ou órgão de controle, desde que exista a possibilidade de 
sanção através do encaminhamento pelo órgão de controle a instâncias com poder legal de sanção, como o Judiciário, por exemplo.

Weber se preocupou com a questão da burocracia ao tratar na sociologia da dominação das formas pelas quais o poder e a dominação moldam a ação social e as relações entre os indivíduos. "Todas as formas de ação social, sem exceção, mostram-se profundamente influenciadas por complexos de dominação." (Weber, 1999:187). O exemplo apresentado por Weber dessa inevitável influência da dominação sobre toda ação social é o que ocorre em uma área aparentemente tão alheia a questões de poder como a da linguística, em que um evento como a elevação de um dialeto a idioma oficial por iniciativa estatal pode promover grandes mudanças, como o desenvolvimento de comunidades línguístico-literárias homogêneas (Weber, 1999:187). Relações aparentemente prosaicas, como o idioma pelo qual as pessoas se comunicam, são, portanto, influenciadas pela estrutura de dominação e não apenas pela cultura ou pela escolha dos indivíduos.

Dois grandes temas da sociologia weberiana são as formas de dominação (em cujo âmbito ele desenvolve os tipos de legitimação do poder de mando: dominação legal, racional ou burocrática, dominação tradicional e dominação carismática) e a sociologia do Estado, em que analisa as formas modernas da dominação racional através do Estado, dos partidos e do Parlamento. A burocracia ocupa posição de destaque porque é o instrumento por excelência da forma moderna de dominação - a dominação racional — e por causa das consequências para a democracia e para o exercício do governo da posição de poder que os funcionários estatais ocupam no Estado. A burocracia, como forma de organização da dominação através da ocupação de funcionários a serviço do soberano, não surgiu com a dominação racional, nem é dela exclusiva, uma vez que as formas tradicionais e patrimoniais de dominação também se organizavam através do trabalho de funcionários; a burocracia moderna, entretanto, tem especificidades que a diferenciam radicalmente da burocracia patrimonial.

As características da moderna burocracia, tanto da pública quanto da do setor privado, são (Weber, 1999:199-200):

v princípio das competências fixas (distribuição fixa das atividades necessárias para a realização dos deveres oficiais, distribuição fixa dos poderes de mando e dos meios coativos, criação de providências planejadas e contratação de pessoas qualificadas segundo critérios gerais),

จ princípio da hierarquia de cargos, 
V documentação dos atos e decisões,

especialização das tarefas,

v profissionalização da força de trabalho dos funcionários (o trabalho na organização burocrática é a ocupação principal dos funcionários e não uma ocupação amadora ou diletante),

v administração de acordo com regras.

No âmbito da dominação baseada no direito público, esses fatores constituem a autoridade burocrática, e, no âmbito da dominação da economia privada, eles constituem a empresa burocrática (Weber, 1999:199). A moderna burocracia pública exerce, portanto, autoridade política, o que a coloca no centro da disputa pela divisão do poder, que se materializa, principalmente, na disputa pelos principais instrumentos de exercício do poder: os cargos públicos. Veremos adiante as consequências da burocratização para a disputa política e a democracia.

O avanço da organização burocrática se deve à sua "superioridade puramente técnica sobre qualquer outra forma [de organização]" (Weber, 1999:212). Mas a afirmação da superioridade técnica da burocracia não significa que Weber compreendesse esse avanço como um fenômeno inexorável, que cumpriria uma função na evolução da sociedade ocidental; ao contrário, nada é mais distante da sociologia weberiana do que análises que não consideram fatores históricos e sociais complexos e de longa duração. Entre os fatores que permitiram o desenvolvimento da burocracia e que moldaram suas características atuais estão fenômenos complexos como o desenvolvimento da economia financeira moderna, a racionalização do direito, a democratização (que ele denomina "fenômeno de massa"), a extensão da intervenção estatal aos domínios mais diversos das atividades humanas e, sobretudo, o desenvolvimento da racionalização técnica (Freund, 2003:171-172).

Vários desses desenvolvimentos contribuíram decisivamente para um aspecto essencial da burocracia moderna: sua ética de disciplina. O desenvolvimento da economia monetária, por exemplo, contribuiu para o estabelecimento da disciplina burocrática ao permitir o pagamento em forma de salário e, portanto, a substituição do sistema de prebendas. Dessa forma, o governante passou a ter maior controle sobre o funcionário, uma vez que o sustento deste deixa de depender de meios privados de coleta de recursos - o que caracteriza o sistema de prebendas - e passa a depender de um montante fixo pago pelo Estado (Weber, 1999:207). A separação entre a esfera privada do funcionário e a atividade oficial, por sua vez, permitiu a profissionalização 
dos funcionários e a atribuição de um caráter objetivo ao cargo, desvinculando assim o funcionário de uma relação pessoal com o governante e estabelecendo a norma e não a vontade do soberano como o fundamento da subordinação e da disciplina (Weber, 1999:208).

A obediência dos funcionários ao detentor do poder não se baseia, entretanto, apenas na legitimidade do soberano, mas também em dois outros meios, que são particularmente atraentes para os burocratas: recompensa material (em suas diversas formas: feudos, prebendas, salário) e honraria social (que também assume diversos formatos: honra dos cavaleiros, privilégios dos estados, honra do servidor público). Ou seja, a obediência não é determinada apenas pela lei, mas também por medo, esperança e pelos interesses (Weber, 1982).

Essa subordinação hierárquica da estrutura da burocracia é tão rigorosa no funcionalismo moderno que Weber chega a compará-la à sujeição dos escravos aos senhores, no sentido de que nenhuma forma de organização da administração da dominação é tão eficaz na garantia de disciplina sobre os funcionários quanto a moderna burocracia, nem mesmo a escravidão:

Somente onde a sujeição dos funcionários ao senhor era absoluta também em sentido puramente pessoal, isto é, no caso da administração por parte de escravos ou empregados tratados como se fossem escravos, podia ser alcançada, pelo menos sob uma direção muito enérgica [do senhor], uma precisão semelhante àquelas que apresentam, no Ocidente da atualidade, os funcionários contratados (Weber, 1999:207).

Essa disciplina do funcionalismo moderno se baseia na normatização de procedimentos, na profissionalização dos funcionários, na especialização do trabalho, na fixação prévia (ou seja, não arbitrária) de competências e de poderes de coação, e é pressuposto absoluto do êxito da administração da dominação (Weber, 1999:540). Todo o aparato administrativo viria abaixo sem a disciplina ética da burocracia: a obediência dos burocratas aos políticos mesmo contra as próprias convicções (Weber, 1999:539).

Entretanto, essa eficácia inigualável da burocracia em estabelecer a disciplina dos funcionários não neutraliza conflitos entre políticos e burocratas pelo poder; a posição de poder da burocracia é muito forte, uma vez que se fundamenta em seus aspectos constitutivos: o controle sobre o conhecimento técnico especializado necessário à condução do Estado, adquirido através da educação formal, e o controle sobre as informações exclusivas advindas do cargo (Weber, 1993:73). Mas esse poder sofre contrapontos e resistências por parte dos políticos, que lutam para não ser subordinados pela burocracia. 
Nas três formas de dominação, o líder que assume o poder tem de lidar com o mesmo problema: dirigir e controlar o "aparelho" (Bendix, 1986). Na dominação tradicional e carismática, o líder consegue obediência pessoal direta, mas, na dominação legal, o problema da liderança e a luta pelo poder são de ordem diferente: como a autoridade é corporificada no domínio da lei, o sucesso na luta pelo poder se manifesta na influência sobre a promulgação das regras. Para obter essa posição o político compete por votos nas eleições e no Parlamento, mas ao longo do exercício de seu mandato ele disputa com a burocracia a supervisão da execução das leis. O controle sobre a implementação administrativa é fundamental, pois a despeito de a titularidade da autoridade na dominação racional legal ser do político, é a burocracia que a exerce. Sem esse controle, a burocracia usurpa o processo de decisão política, de acordo com sua tendência de transformar questões políticas em problemas administrativos (Bendix, 1986:337-338).

O poder da burocracia é, portanto, muito grande, e ela sempre procura aumentá-lo, e uma de suas principais "armas" é a manutenção do segredo sobre seus conhecimentos e intenções (Weber, 1999:225): "Tendencialmente, a administração burocrática é sempre uma administração que exclui o público" (Weber, 1999:225).

A manutenção de certas questões fora da discussão pública pode se justificar em áreas sensíveis como a militar e a diplomática, em que o sigilo pode ser necessário à eficiência da atuação governamental. O segredo, entretanto, deve ser combatido quando tem como motor o puro interesse no poder, o interesse da burocracia em se contrapor ao Parlamento ou ao monarca e de ocupar uma situação privilegiada (Weber, 1999:226).

Uma vez que o conhecimento especial se torna, em proporção crescente, a base da posição de poder dos detentores de cargos oficiais, constitui há muito tempo um objeto de preocupação do 'senhor' a maneira em que pode aproveitar-se deste conhecimento sem renunciar a favor dele, mantendo, ao contrário, sua posição dominante (Weber, 1999, p. 227).

A burocracia, portanto, permite a dominação, mas também a desafia (Weber, 1999:537). Essa sua dupla face gera a luta latente entre funcionalismo especializado e autocracia pela direção suprema do Estado, uma disputa que já existia muito tempo antes da afirmação da moderna burocracia e que permanece presente nas democracias contemporâneas. À medida que o soberano se torna cada vez mais diletante (relativamente à crescente especialização dos funcionários), ele precisa se aproveitar do conhecimento especial, 
ao mesmo tempo que se defende do poder crescente deste conhecimento e mantém sua posição dominante diante de seus detentores - a burocracia (Weber, 1999:537).

A expansão da burocracia por toda parte não significa, necessariamente, o aumento universal de seu poder dentro do Estado. A supremacia técnica da burocracia e sua indispensabilidade não implicam, necessariamente, poder social ou político (os proletários também são indispensáveis, mas isso não lhes atribuiu automaticamente poder político) (Weber, 1999:225). Há resistência a esse aumento de poder da burocracia, na forma da consulta a outros especialistas, de criação de órgãos deliberativos locais ou órgãos centrais parlamentares (Weber, 1999:225). Uma das formas que os políticos encontraram para se fortalecer nesse combate e se contrapor ao poder burocrático crescente foi a politização de uma parcela da burocracia, em especial do alto escalão. $\mathrm{O}$ desenvolvimento da disputa política em um sistema que exigia treinamento na luta pelo poder e nos métodos dessa luta levou à divisão dos funcionários públicos em duas categorias: funcionários especializados e funcionários políticos (Weber, 1999:538). Os funcionários políticos se caracterizam por poderem ser transferidos, demitidos ou colocados à disposição, mas principalmente por terem a tarefa, e este é o componente político de sua posição, de manter a ordem no país, ou seja, as condições de dominação existentes (Weber, 1999:538).

Outra forma de resistência dos políticos ao aumento de poder dos burocratas é gerar disputas ou concorrência entre especialistas (o dirigente questiona um especialista por meio de outro para chegar a uma conclusão própria e ter certeza de que não lhe foram sugeridas decisões arbitrárias) (Weber, 1999:228). Weber comparou a forma de atuação adiante da burocracia de muitos dirigentes atuais à estratégia adotada por Frederico Guilherme, rei prussiano no começo do século XIX: para ao mesmo tempo usar o conhecimento da burocracia e dele se defender, o rei se ausentava das sessões ministeriais, manifestando sua opinião posteriormente em relatórios escritos ou decretos, e depois de discutir com servidores pertencentes ao gabinete, que era constituído por funcionários pessoalmente devotados ao rei. Dessa forma, o soberano não se expunha diretamente durante a tomada de decisões e, diante do fracasso ou impopularidade de alguma decisão, ele poderia "usar" o gabinete como anteparo do descontentamento popular (à semelhança do moderno blame shifting). Por outro lado, o gabinete permitia ao soberano contrapor-se ao domínio da burocracia especializada sobre as informações a respeito da administração (Weber, 1999:228). Este exemplo mostra dois instrumentos muito comuns de controle sobre a burocracia: a nomeação de funcionários pessoalmente muito próximos ou ideologicamente afinados com o dirigente para 
cargos de direção da burocracia, e a manipulação da estrutura organizacional de forma a criar contraposições e mútuo controle entre órgãos burocráticos.

Apesar de os exemplos citados até agora poderem dar a impressão de que os conflitos entre as tendências da democratização e da burocratização interessam apenas ao governante "de plantão" e aos funcionários, essa conclusão seria falsa, pois esses conflitos constituem uma ameaça ao sistema político como um todo. É nesse sentido que se afirma que as principais ameaças da burocratização à democracia são representadas pelas seguintes questões:

como salvar resquícios de uma liberdade de ação individual?

v como controlar e manter os limites do funcionalismo estatal? E qual poder fará isso?

v como suprir limites internos da burocracia, ou seja, sua incapacidade de tomar decisão? (é a questão mais importante, segundo o autor) (Weber, 1999:542).

A ameaça da burocracia tem duas faces: a ameaça aos direitos individuais e à liderança política responsável (Weber, 1993:54). O crescimento do poder da burocracia significa uma ameaça potencial à garantia dos direitos humanos. Por outro lado, o limite intrínseco da burocracia, ou seja, sua incapacidade de assumir responsabilidades políticas significa que ela precisa de um líder responsável. O poder que pode se contrapor à burocracia é o poder democrático: sem parlamento, o governo por funcionários é forma pura de dominação burocrática acima de qualquer controle, e por parlamento Weber quer dizer tanto a expressão de um mínimo de aceitação dos governados em relação à dominação exercida por meios burocráticos - com representação via partidos livres e não via corporações - , quanto o controle político sobre a burocracia, através do direito de arguição e investigação do parlamento sobre a administração. Os controles dos políticos sobre a burocracia são necessários porque a hierarquia e o controle hierárquico não são suficientes para manter a disciplina da burocracia: "Enquanto os escalões inferiores da hierarquia oficial são controlados e criticados pelos superiores, falhava na Alemanha todo controle, tanto o técnico quanto o político, em relação às instâncias supremas, isto é, as que se ocupam da 'política"' (Weber, 1999:565).

Na discussão sobre o funcionamento do Parlamento alemão e suas relações com a burocracia, Weber desenvolveu os temas da responsabilidade política e do papel do controle sobre a burocracia como condição para a atuação política independente e responsável dos políticos. O controle do Parlamento sobre a burocracia é uma das formas de atuação positiva do Parlamento: definir 
políticas, liderar o governo, assumir a responsabilidade pela direção do Estado e pela inovação (em contraposição a sua atuação "negativa" de aprovar ou rejeitar o orçamento). Os burocratas não podem assumir o papel de renovação, pois a natureza de seu trabalho é a manutenção da ordem, da rotina, e, mais importante, eles não podem assumir responsabilidades políticas. Nesse sentido, controlar a direção do funcionalismo é a primeira tarefa fundamental do Parlamento:

E não apenas as tarefas atribuídas às supremas instâncias centrais [da burocracia], mas também a instrução em cada questão particular nas instâncias inferiores, mesmo que seja de caráter puramente técnico, podem ser politicamente importantes, determinando-se sua solução por aspectos políticos. Os políticos têm que constituir o contrapeso do funcionalismo. Mas a isto opõe resistência o interesse de poder das instâncias dirigentes da burocracia, as quais sempre aspirarão à liberdade incontrolada, à monopolização dos cargos de ministro para a ascensão de funcionários (Weber, 1999:564).

Nesta passagem, Weber prenunciou os temas da literatura contemporânea sobre burocracia e política, como o poder da burocracia de ponta de linha (os street level bureaucrats, cuja atuação não se limita à implementação das políticas públicas, mas avança sobre a tomada de decisões típicas de formuladores), a relevância política dos controles administrativos de procedimentos enquanto instrumentos de controle dos políticos sobre a burocracia (visão de "MacNollGast" dos procedimentos administrativos como fire alarms — os procedimentos não são apenas instrumentos de garantias legais ou do rule of Law, mas insumo para o controle do Congresso sobre a atuação do Executivo) (McCubbins, Noll e Weingast, 1987), e a importância da análise diferenciada da burocracia quanto às formas de provimento dos cargos (cargos de livre nomeação e cargos providos por concurso/mérito devem ser analisados de forma diferente, pois os primeiros se assemelham aos cargos políticos e os segundos representam a burocracia meritocrática a que Weber se refere) (Loureiro e Abrucio, 1999).

A falta de controle do Parlamento sobre a burocracia gera dois tipos de problemas: a invisibilidade da atuação da burocracia perante a população e, no extremo, a irresponsabilidade dos parlamentares em face dos desafios do Estado. Comparando o funcionamento das comissões parlamentares inglesas e alemãs, Weber afirmou que, na Alemanha,

os problemas com os quais têm que lutar os funcionários na realização de seu trabalho não se manifestam, em nenhuma parte, de forma visível. Jamais pode- 
rá ser compreendido e estimado seu desempenho, jamais serão superados aqueles ataques estéreis contra o 'São Burocrático', que tomam o lugar da crítica positiva, se continuar a situação da dominação incontrolada dos funcionários (Weber, 1999:565).

O acompanhamento das discussões nas comissões do Parlamento inglês pela imprensa e pela população era considerado por Weber indicadores da integridade do funcionalismo britânico e do alto nível de educação política do país, mas ele identificou o fundamento dessa integridade e dessa educação no direito de arguição do Parlamento inglês. Além de promover o escrutínio público da atuação da burocracia e a participação responsável dos dominados na gestão do domínio, o poder de controlar a administração através do direito de arguição é pressuposto indispensável para a transformação do Parlamento em um lugar de seleção dos líderes políticos responsáveis pela direção da nação (Weber, 1999:566). Sem o poder de convocar funcionários para argui-los e interrogá-los e sem o poder de inspeção dos documentos oficiais o Parlamento alemão não passava de uma casa de demagogos, cujas falas não tinham importância para a vida da nação e cuja principal motivação passava a ser a busca por prebendas. Os políticos somente assumirão seu papel de liderança política quando tiverem poder de influenciar a administração e de dirigir a burocracia.

Voltemos, agora, às duas questões com que iniciamos a discussão dos textos de Weber: a expansão da burocracia devido à sua superioridade técnica, e o conflito latente entre burocratização e democratização.

A superioridade técnica da burocracia continua determinando sua expansão nos domínios público e privado, através do aprofundamento de suas principais características: profissionalização e especialização das tarefas, normatização e documentação, controle e disciplina. O desenvolvimento da técnica, como o aprimoramento da tecnologia da informação, não combate a burocratização nesse sentido definido por Weber. Ao contrário do que acredita o senso comum, o desenvolvimento de algumas técnicas promove o controle dos dirigentes sobre a organização e aprofunda sua "função" disciplinadora e, portanto, reforça a burocratização. No setor público brasileiro, onde a aplicação dos sistemas de informação está em incipiente expansão, eles têm possibilitado maior controle hierárquico nas organizações; no governo estadual de São Paulo, por exemplo, a informatização do processo de compras teve como principal resultado o maior controle sobre a atuação da burocracia da "ponta" do sistema (Sanchez, 2005). 
A outra questão fundamental para Weber é o conflito latente entre burocratização e democratização, expresso, entre outras formas, nas disputas sobre o controle da burocracia em nome da democracia. A burocracia moderna, como já vimos, é sinônimo de disciplina e, no âmbito estatal, também de autoridade política. Sua força está em ser, ao mesmo tempo, objeto (enquanto instrumento de dominação do líder sobre os dominados) e sujeito (pois controla os meios de dominação, a técnica e o conhecimento advindo do cargo). Por causa disso, a burocracia carrega em seu bojo dois princípios conflitantes: a vocação para a subordinação ao líder político e o germe da ambição do exercício autônomo da autoridade. Na democracia, a ameaça da perda de supremacia pelo líder político para a burocracia é mais que uma ameaça à ordem pública, pois ela também coloca em risco a liberdade individual como valor e como fundamento da ação política (sem liberdade de escolha e de exercício do poder, os políticos não são responsáveis por suas ações).

A democracia espera que o poder se organize de forma a respeitar a igualdade legal entre os indivíduos com base em normas, portanto, que se organize de forma burocrática, mas, ao mesmo tempo, a democracia se volta contra a resistência da burocracia em ser controlada e dirigida pela sociedade e pelos políticos. As relações entre política e burocracia são naturalmente ambivalentes:

a 'democracia', como tal [como igualdade jurídica dos dominados], apesar de fomentar inevitavelmente, mas sem querer, a burocratização, e também por causa disso, é inimiga do 'domínio' da burocracia, podendo criar, neste papel, rupturas e obstáculos muito sensíveis para a organização burocrática (Weber, 1999:224).

Essa questão da relação entre política e burocracia é inseparável da discussão dos papéis dos políticos e dos burocratas. As diferenças entre eles residem parcialmente na natureza da atuação esperada de cada um e principalmente na natureza de suas responsabilidades. A natureza de suas atuações é semelhante, uma vez que se exigem capacidades de decisão e de organização de ambos:

a ideia de que o funcionário se limite a cumprir deveres subalternos rotineiros e somente o dirigente tenha que realizar as tarefas 'interessantes', que requerem capacidade intelectual, é completamente absurda e somente pode surgir em um país que não está a par da forma em que se administram seus assuntos e da atuação de seus funcionários públicos (Weber, 1999:543). 
A diferença de suas responsabilidades significa que o funcionário só deve responder por seu dever, ou seja, pelo cumprimento de ordens (o que não significa que não possa e, mais que isso, que não deva fazer objeções a ordens que considere equivocadas, mas que deve cumpri-las se o governante reafirmá-las, ainda que continue discordando delas), enquanto a responsabilidade do político é em relação à luta pelo poder e pelos acordos que realiza, enfim, por suas escolhas. O líder é pessoal e exclusivamente responsável, enquanto a natureza do servidor é ser mau político e, principalmente, político irresponsável (Weber, 1982).

Sendo a burocracia uma ameaça à democracia de que não podemos, apesar disso, prescindir, a questão, então, é: como organizar os sistemas do controle democrático entre burocratas e políticos? Como organizar um sistema de equilíbrio inevitavelmente precário e instável dada a natureza conflituosa da relação entre política e burocracia? Vejamos, a seguir, como a literatura contemporânea tem respondido, ou não, a essas perguntas e desafios.

\section{A relação entre política e burocracia no Brasil e nos EUA}

O debate sobre a relação entre política e burocracia na literatura norte-americana é marcado por duas características: a referência a um debate que remonta ao texto de Woodrow Wilson de 1887 sobre a relação entre política e administração, e a intensa referência às visões liberais e republicanas sobre a esfera pública. Os textos que fazem a "genealogia" dessa temática referem-se ao debate inaugurado na época da primeira reforma administrativa dos EUA, no final do século XIX, sem referência explícita à obra de Weber.

A ideia básica de Woodrow Wilson (acadêmico que exerceu a presidência dos EUA entre 1913 e 1921), ou ao menos a ideia apontada na literatura como o antecedente do debate atual, é a de separação entre burocracia e política (Eisner e Meier, 1990). Wilson defendia a separação clara entre as atividades dos burocratas e as dos políticos, de forma que os políticos decidissem sobre as escolhas das políticas públicas, e os burocratas apenas as implementassem, como agentes técnicos e neutros. ${ }^{1}$

\footnotetext{
${ }^{1}$ Wilson escreveu seu trabalho no contexto da discussão sobre a primeira reforma administrativa norte-americana, que foi aprovada em 1883, na forma de uma lei conhecida como Pendleton Act (Wilson, 1887). Essa reforma instaurou a obrigatoriedade de concurso público para a escolha de algumas categorias de funcionários públicos e foi o primeiro passo de um processo, que se estendeu ao longo do século XX, de constituição de uma burocracia meritocrática.
} 
É interessante notar a oposição entre as ideias de Wilson e as Andrew Jackson, que ocupou a Presidência um século antes, entre 1829 e 1837, e que encarnou o "espírito" das relações entre política e burocracia nesse período. Embora a literatura não aponte o debate direto entre suas ideias, fica clara a posição de Wilson em favor da noção de burocracia neutra e meritocrática, em relação à defesa de Jackson do que ele denominava como burocracia representativa.

Jackson defendia o sistema de espólio (spoils system) com base na ideia de burocracia representativa (Divine, 1979). O sistema de espólio se caracteriza pela distribuição dos cargos da burocracia pública entre os eleitores e correligionários do candidato vencedor à Presidência. Para Jackson, essa era uma forma de reforçar a democracia, pois os cidadãos comuns trazidos para a administração representariam os diversos grupos ou setores da sociedade que poderiam não estar representados, ou não estar adequadamente representados, no Congresso. O espírito do sistema de espólio não era, portanto, antirrepublicano, como o é o do clientelismo e o do sistema de prebendas. A concepção da distribuição do espólio entre os vencedores não era a de atribuição de benesses aos aliados com recursos públicos, mas, sim, uma forma de reforçar a democracia representativa. O spoils system permitia que, através da escolha de pessoas comuns, que representavam as concepções e a moral de seus concidadãos, a representatividade do sistema democrático fosse aperfeiçoada ou aprofundada.

A ideia de burocracia representativa não pode ser colada diretamente à de clientelismo; ela realça, na verdade, a ligação antiga entre burocracia e democracia no debate norte-americano. Essa comparação será desenvolvida adiante. Continuemos na comparação entre burocracia meritocrática e representativa.

No sistema de espólio, a escolha de servidores públicos civis por critérios políticos não se opunha à escolha por critérios técnicos. Havia, sim, uma sobreposição, uma coincidência entre político e técnico, mas de forma que o político não se reduzisse ao técnico e permanecesse com escopo e amplitude maiores que o técnico. Ou seja, não interessava apenas escolher, entre os cidadãos, aquele que sabia mais e estava mais capacitado para assumir o cargo. Tratava-se de escolher, ao mesmo tempo, conforme critérios técnicos mínimos e conforme a possibilidade de representação de grupos sociais dentro do serviço público federal (Divine, 1979). Uma consequência importante da burocracia representativa é que ela permitia trazer a política para dentro da burocracia, e isso significava reproduzir as divisões e os interesses da sociedade dentro do Executivo, de forma tão legítima quanto as eleições pro- 
moviam a representação do povo dentro do Congresso. E o que legitimava a representatividade da burocracia era não apenas o princípio democrático da representação, mas a visão pluralista da sociedade, a visão da sociedade como dividida em grupos com interesses diferentes e igualmente legítimos perante o poder público.

Na oposição entre burocracia representativa e burocracia neutra não estava apenas o debate sobre a necessidade de conhecimento técnico, mas, principalmente, sobre a concepção de política e de democracia. A possibilidade de cidadãos comuns exercerem funções públicas, fossem elas legislativas ou administrativas, era típica da exaltação norte-americana do homem comum. Na Europa, ao contrário, a política era a esfera privativa do sábio e do experiente, daquele capaz, por sua condição natural ou social, de exercer o poder (Divine, 1979). A burocracia representativa se opunha a tal diferenciação entre os homens, colocando-se, portanto, ao lado da tradição americana que prezava o homem comum, bem como da tradição da igualdade e da democracia representativa.

Isso não significa que os defensores da burocracia meritocrática fossem contra a igualdade como direito civil básico e contra a democracia representativa. Mas a institucionalização da burocracia meritocrática, a partir de fins do século XIX, obrigou a uma reconsideração da relação entre política e burocracia no quadro dessas instituições. Quando a burocracia passa a ser o lugar dos experts, dos que detêm conhecimento técnico e profissional, surge espaço para a oposição entre burocracia e política. A profissionalização da burocracia através do sistema meritocrático pressupõe a formação de um grupo social com um ethos diferente, tanto em relação aos demais grupos da sociedade (pois os burocratas administram a coisa pública, e não um negócio privado), quanto em relação aos políticos (cuja posição, em relação à definição das políticas, é de comando, e que assumem a responsabilidade pelos seus resultados - ao contrário dos burocratas, que são comandados e politicamente irresponsáveis).

Dessa diferença quanto à responsabilidade de burocratas e de políticos surge espaço para se pensar a ideia do controle sobre a burocracia. Na medida em que os burocratas, com a reforma meritocrática e o abandono da burocracia representativa, deixam de ser cidadãos comuns com a função de legitimamente representar grupos e interesses da sociedade dentro do Estado, surge a possibilidade de eles não serem fiéis às escolhas ou preferências do povo. No sistema de espólio, se os burocratas eram, antes e acima de tudo, cidadãos como todos os outros, não havia como questionar sua fidelidade aos interesses do povo. A consequência natural do surgimento dessa "desconfiança" contra 
a burocracia de mérito é a necessidade de controlar os burocratas para que eles sejam fiéis aos interesses dos representantes do povo, dos únicos representantes que permaneceram no Estado: os legisladores. A outra consequência natural é a possibilidade de pensar a burocracia como uma fonte de ameaça à democracia.

Esse novo formato das relações entre política e burocracia, baseado na burocracia meritocrática, encontra respaldo no constitucionalismo, como antes a burocracia representativa encontrava respaldo nas instituições da igualdade civil e da representação democrática. O constitucionalismo norte-americano está fundado na afirmação da soberania do poder Legislativo, como único ou principal poder legitimamente competente para determinar a direção da política (Long, 1952). A força dessa doutrina e de sua prática mostra-se na divisão do controle sobre a burocracia civil entre o Legislativo e o Executivo. Muitos órgãos burocráticos (denominados agencies) norte-americanos têm suas diretrizes definidas por comissões do Congresso e somente a elas respondem, e uma das principais formas de controle político da burocracia é aquela exercida pelo Congresso.

As questões sobre a autonomia da burocracia e sobre sua captura pelos interesses privados aparecem na literatura norte-americana de forma a problematizar o caráter democrático ou não da autonomia e da captura, e não o caráter do Estado e suas formas de institucionalização. Nesse sentido, os grandes problemas que a burocracia meritocrática impõe ao regime democrático, segundo os estudiosos norte-americanos, são o grau de discricionariedade da burocracia e o risco de captura das agências executivas por interesses de minorias. A discricionariedade da burocracia (que nada mais é do que certo grau de autonomia de decisão da burocracia) é um problema, porque põe nas mãos de outros agentes que não os legisladores — que são os legítimos representantes da vontade do povo - a decisão sobre a direção das políticas públicas. Disso deriva seu caráter antidemocrático, e a necessidade de controlar o modo pelo qual a burocracia exerce sua inevitável discricionariedade. A captura das agências governamentais pelos interesses privados, por sua vez, é antidemocrática porque caracteriza a sobreposição do interesse da minoria sobre o interesse geral ou da maioria, cuja guarda é atribuição do governo. A captura é uma anomalia da representação democrática dos diversos interesses sociais, e o principal remédio para esse desvio também é o controle político sobre a burocracia.

Sinteticamente, a relação entre política e burocracia nos EUA apresentou duas formas distintas. Uma baseada na burocracia representativa, respaldada nas instituições da igualdade civil e da representatividade democrática, e 
em que a relação entre política e burocracia se estabelecia como sobreposição e indiferenciação. A outra, baseada na burocracia meritocrática, respaldada no constitucionalismo norte-americano e em que a relação entre política e burocracia se estabelece como de complementaridade (devido à divisão das tarefas entre políticos e burocratas) e de contraposição (graças à oposição das suas responsabilidades).

$\mathrm{Na}$ literatura brasileira, a política e a burocracia sempre foram vistas como opostas e conflitantes. A história da relação entre política e burocracia no Brasil é contada em termos de oposições entre a racionalidade da política (distributiva) e a racionalidade da burocracia (eficiência), e entre a burocracia politizada (instrumentalizada pelo clientelismo ou capturada por grupos da sociedade) e a burocracia meritocrática (supostamente neutra) (Nunes, 1999). O que sempre se analisou e apontou na literatura brasileira foram o clientelismo e a ineficiência da burocracia. O clientelismo é conceito corrente da análise sobre a prática política e sobre as formas de organização de setores da administração pública. Enquanto prática política, o clientelismo se opõe à política ideológica - a representação de interesses da sociedade nas esferas públicas e estatais é distorcida pela forma patrimonial de relação entre políticos e parcela significativa da sociedade. Por outro lado, enquanto forma de organização da administração pública, o clientelismo se opõe à burocracia meritocrática e neutra, que leva à prática de insulamento burocrático e seus corolários: os anéis burocráticos e o tecnocratismo.

Além disso, os estudos sobre burocracia, no Brasil, não têm como foco a relação entre burocracia e democracia, mas entre burocracia e formação do Estado. O que talvez explique essa diferença de foco em relação à literatura norte-americana é, principalmente, a diferença de perspectiva analítica adotada, que faria estudiosos norte-americanos e brasileiros olhar para problemas diferentes. Assim, se o pluralismo é uma das principais vertentes analíticas nos EUA, no Brasil predominou, nas últimas décadas, o neomarxismo do Estado (Marques, 1997). Nessa perspectiva marxista, os temas principais no estudo sobre o Estado são sua autonomia e as alianças entre elites estatais e elites econômicas. O problema teórico que se busca resolver é identificar os atores que exercem a autonomia do Estado, bem como as formas pelas quais os agentes econômicos conseguem manter a ação do Estado na direção de seus interesses. Assim, a autonomia dos burocratas aparece como a comprovação de certo grau de autonomia do Estado, e não como uma ameaça aos legítimos interesses da sociedade. Da mesma forma, as alianças entre as classes econômicas e as elites estatais são a comprovação da instrumentalização do Estado 
pelos interesses da classe dirigente, e não a hegemonia não democrática de interesses de uma minoria. ${ }^{2}$

No Brasil, não há um fundador do debate, que exerça um papel semelhante ao que Woodrow Wilson ocupou na literatura norte-americana, nem há a preocupação, de forma direta e explícita, com a democracia, mas sim com a formação e a institucionalização do Estado enquanto poder público. É interessante perceber que, nos EUA, aparecem as mesmas questões sobre autonomia da burocracia e sobre sua captura pelos interesses privados, mas de forma diferente, posto que se problematiza não o caráter do Estado e suas formas de institucionalização, mas o caráter democrático ou não da autonomia e da captura.

Como já vimos, os grandes problemas que a burocracia meritocrática impõe ao regime democrático, segundo os estudiosos norte-americanos, são o grau de discricionariedade da burocracia e o risco de captura das agências executivas por interesses de minorias. A discricionariedade da burocracia é um problema porque coloca nas mãos de outros agentes que não os legítimos representantes da vontade do povo (os legisladores) a decisão sobre a direção das políticas públicas. Disso deriva seu caráter antidemocrático, e a necessidade de controlar o modo pelo qual a burocracia exerce sua inevitável discricionariedade. A captura das agências governamentais pelos interesses privados, por sua vez, é antidemocrática porque caracteriza a sobreposição do interesse da minoria sobre o interesse geral ou da maioria, cuja guarda é atribuição do governo. A captura é uma anomalia da representação democrática dos diversos interesses sociais. O principal remédio para esse desvio também é o controle político sobre a burocracia.

Essa diferença de perspectivas analíticas talvez seja um dos fatores responsáveis pela ausência do tema do controle político sobre a burocracia na literatura brasileira que trata do tema da relação entre política e burocracia. A necessidade de controle político sobre a burocracia não é um problema que se coloca na perspectiva analítica em que o Estado é, inevitavelmente, um instrumento das elites econômicas. Nessa perspectiva, o controle político seria, talvez, interpretado como instrumento inócuo diante dessa estrutura intrinsecamente desigual, inevitavelmente manipulada e utilizada como instrumento de dominação. Carlos Estevam Martins identificou a ojeriza dos cientistas sociais brasileiros em relação ao tema do controle político, qualificando-a como uma atitude preconceituosa e irresponsável:

\footnotetext{
${ }^{2}$ Para um debate mais profundo dessa literatura ver Loureiro, Olivieri e Martes (2010).
} 
Este artigo visa apenas apresentar, sem maiores pretensões, algumas anotações a respeito de um assunto que é meio tabu no contexto brasileiro das ciências sociais: a questão do controle. Em geral, as pessoas preferem evitar esse tema, temendo talvez provocar mal-entendidos e reações de reprovação, carregadas de emocionalidade negativa. Esse clima, tipicamente preconceituoso, talvez se deva à própria ambiguidade do assunto. A existência de controles pressupõe sempre dois lados - o do controlador e o do controlado - sendo que não gostamos do primeiro, tido como algoz, e simpatizamos com o segundo, tido como vítima. O povo, na condição de classe dominada, é controlado, enquanto a classe dominante, por definição, é controladora. Estar a favor dos controles, deduz-se, é atitude muito suspeita, sinal quase certo de que não se está do lado dos oprimidos.

Do ponto de vista do credo democrático, porém, tal argumentação é inaceitável. Nas democracias, presume-se que o povo detém o poder soberano e, portanto, é ao povo que cabe a função de controlador. Estar a favor dos controles, para os democratas, nada implica de antipopular: ao contrário, é ser consequente (Martins, 1989:5, grifos nossos).

A perspectiva de análise que privilegia a estrutura do Estado soma-se a outra influência analítica, a weberiana, no sentido de concentrar a atenção dos estudiosos na estruturação do Estado e da sociedade, em detrimento da esfera da política enquanto representação e jogo de interesses. As mais influentes análises sociais e históricas do Brasil, como as de Sérgio Buarque de Holanda, Raymundo Faoro e Simon Schwartzman, apontam como fundamental a estrutura social patrimonialista, e têm Weber como principal referência. Esses autores apontam a "ausência de encaminhamento tipicamente burguês e classista do desenvolvimento nacional, baseada na representação de interesses" (Campante, 2003). Ou seja, essa perspectiva de análise também coloca como central a figura do Estado (e a do estamento ou das elites), em contraposição à sociedade e aos interesses difusos. Antes da preocupação com a democracia, temos, portanto, a preocupação com a modernidade e com a construção das instituições modernas: o Estado racional-legal, a sociedade plural (sempre ausente e abúlica, na interpretação de Faoro), a burocracia meritocrática e republicana. ${ }^{3}$

\footnotetext{
${ }^{3}$ Seria interessante estabelecer um paralelo entre a grande influência do pensamento weberiano sobre os clássicos do pensamento social brasileiro e sobre as análises do Estado e da burocracia com a grande ausência de citações a Weber nos trabalhos norte-americanos. Uma pergunta interessante seria: por que o patrimonialismo em que "degenerou" a burocracia representativa de Andrew Jackson não foi analisado nos termos weberianos de tradição versus modernidade?
} 
Essas análises fundadas no patrimonialismo reforçam a visão da política como domínio do clientelismo. Esse é outro fator que também afasta os estudiosos brasileiros do tema do controle democrático da burocracia: a identificação da política com a prática do clientelismo. Se a política, quando dentro da administração pública, significa clientelismo, ou seja, distribuição de recursos públicos segundo critérios patrimonialistas ou, em outras palavras, critérios não universalistas e não democráticos, as soluções que necessariamente se apresentam são tirar a política da burocracia, reforçando a dicotomia entre política e burocracia, e isolar a burocracia da política, insulando-a. O problema dessa solução está em que, reforçando a dicotomia, nega o caráter político das decisões da burocracia (e o discurso da neutralidade da técnica é importante aliado dessa negação). E, ao negar o caráter político das decisões burocráticas, coerentemente reduz ou anula a necessidade de controle político sobre a burocracia.

Vejamos, a seguir, como, a despeito da não problematização dos controles políticos sobre a burocracia no Brasil, é possível analisar seu estado atual.

\section{0 controle dos políticos sobre a burocracia}

Uma nova vertente de análise da política brasileira, que não se filia aos estudos sobre a formação do Estado nem aos trabalhos de cunho mais sociológico, abriu novas perspectivas, ainda pouco exploradas, para o estudo sobre a burocracia. É a vertente neoinstitucional, que se diferencia pelo fato de permitir a análise da política e das instituições políticas (sistema de governo, regras eleitorais, relações entre Executivo e Legislativo etc.) como entes analiticamente autônomos em relação à estrutura social, à estrutura de classes, ao desenvolvimento econômico-social. Na literatura internacional, essa vertente deu origem a novos estudos de política comparada e sobre o processo de democratização, e entre os trabalhos que exerceram maior influência no debate latino-americano e nacional estão os de Juan Linz, Alfred Stepan, Scott Mainwaring e Arend Lijphart, que compararam as características institucionais dos sistemas presidencialista e parlamentarista quanto a sua capacidade de produzir governos democráticos estáveis.

No Brasil, essa vertente deu origem a um debate em torno da governabilidade do sistema presidencialista na Nova República. O diagnóstico de Mainwaring (1997), afirmando a ingovernabildade do sistema político brasileiro devido à combinação das características do presidencialismo, do multipartidarismo e do federalismo, deu origem a uma série de estudos que con- 
firmavam (Lamounier, 1994) ou contestavam a tese da ingovernabilidade (Limongi e Figueiredo, 1998). Esse debate produziu muitos estudos inovadores sobre as instituições políticas brasileiras, mas poucos trabalhos sobre o papel da burocracia como lócus de poder e ator político, e nenhum sobre o controle democrático dos políticos sobre a burocracia.

Na literatura norte-americana, ao contrário, a perspectiva neoinstitucional avançou no debate sobre esse tema, e aponta os termos em que essa discussão pode ser adotada no Brasil: a identificação dos mecanismos de controle sobre a burocracia e sua compreensão na perspectiva do funcionamento do sistema político. Esses mecanismos são: nomeação política, controle orçamentário, reorganização da estrutura administrativa, personnel Power, ${ }^{4}$ monitoramento (oversight) e legislação (Wood e Waterman, 1991). Nos EUA, esses mecanismos de controle promovem a transparência da administração pública e a responsabilização dos políticos graças ao equilíbrio e à constante competição entre os Poderes Executivo e Legislativo. A distribuição equilibrada desses instrumentos de controle entre o presidente e o Congresso garante um controle efetivo entre os poderes (checks and balances), e a competição de ambos pelo controle sobre a burocracia promove sua transparência e responsabilização.

Os principais estímulos a que a burocracia norte-americana responde são compartilhados pelos dois poderes: nomeação e orçamento (Wood e Waterman, 1994). O presidente tem o poder de nomear os ocupantes de diversos cargos de direção da burocracia, mas esse poder não é exercido de forma incontrastada, uma vez que há a necessidade de aprovação desses nomes pelo Congresso. As negociações sobre os nomes apresentados pelo presidente ao Congresso levaram à institucionalização de um processo semiformal e relativamente transparente de escolha desses nomes, a clearence, pelo qual as credenciais pessoais e profissionais do candidato são avaliadas pelo Executivo e negociadas com a comissão responsável por sua aprovação (Mackenzie e Shogan, 1996).

Embora o sistema político norte-americano de separação de poderes tenha sido desenhado antes do crescimento da administração pública, essa ampliação foi acompanhada do desenvolvimento, tanto pelo Executivo quanto pelo Legislativo, de formas de monitoramento sobre a ação da burocracia (Aberbach, 1990). A agência de supervisão sobre o Executivo — Government Accountability Office (GAO) — foi criada em 1921 por determinação do Con-

\footnotetext{
${ }^{4}$ Poder de escolher os senior career executives, que são os funcionários estáveis da burocracia norte-americana.
} 
gresso. Ao longo do século XX, o Executivo reagiu ao crescimento da capacidade do Congresso de acompanhar as ações do governo através do fortalecimento do gabinete presidencial, em especial do Office of Management and Budget (OMB), responsável pela revisão da legislação emanada dos ministérios e de muitos órgãos autônomos, além do acompanhamento da elaboração e execução do orçamento (Wood e Waterman, 1991).

Para trazer esse debate para o Brasil, é preciso perguntar "Como se constroem controles políticos democráticos sobre a burocracia?" tendo em vista as características do sistema político brasileiro: presidencialismo consensual, federalismo forte, multipartidarismo e partidos fracos (Palermo, 2000). A questão é como essas características influenciam a relação entre políticos e burocracia, mais especificamente a relação de direção dos funcionários especializados pelos funcionários políticos e pelos próprios políticos. Por causa do presidencialismo consensual, o presidente divide a direção da burocracia com os membros da coalizão e, por causa do multipartidarismo, da fraqueza dos partidos e do federalismo, essa repartição é feita de acordo com critérios não exclusivamente partidários nem técnicos, mas também federativos (considerando as lideranças regionais dos partidos) e pessoais (do presidente da República), entre outros (Loureiro e Abrucio, 1999). Uma das principais faces dessa repartição é o preenchimento dos cargos de direção da burocracia por membros da coalizão ou por pessoas por eles indicados. O problema dessa distribuição de milhares de cargos entre os aliados políticos do governo não é a politização em si que ela acarreta, mas a existência, ou não, de mecanismos democráticos de controle sobre a atuação desses nomeados.

A politização sempre ocorre, até em regimes autoritários, pois alguma visão sobre a direção governamental das políticas públicas sempre prevalece sobre outras, seja em decorrência da definição autocrática por parte do governante, que privilegia alguns grupos em detrimento de outros, seja graças à vitória nas urnas de uma corrente ou de um partido político. A questão é como garantir a accountability após as eleições, ou seja, desde a nomeação de pessoas que não necessariamente foram eleitas até sua atuação na direção das políticas públicas. Nesse sentido, os instrumentos de controle sobre a burocracia à disposição do Congresso e do presidente funcionam, ou deveriam funcionar, como formas de transparência e de responsabilização das escolhas sobre quem são os nomeados e sobre quais são os acordos políticos envolvidos na nomeação. Como já vimos, os controles políticos são necessários porque há delegação de poder. Os políticos recebem delegação do povo para governar e por isso precisam, em primeiro lugar, ser controlados quanto à possibilidade de abuso de poder, e, em segundo lugar, mas não menos importante, preci- 
sam prestar contas do que fizeram com esse poder. Os políticos, por sua vez, delegam parte desse poder para a burocracia, e por isso precisam, da mesma forma, impedir abusos e garantir o controle sobre a atuação dessa burocracia. Os políticos precisam garantir a supremacia sobre os burocratas, ou seja, garantir que a burocracia respeite e acate a definição sobre políticas públicas dos políticos; do contrário, o princípio democrático deixa de ser respeitado.

Na relação de delegação do presidente para a burocracia, o presidente e o gabinete (ministros) precisam tomar contas da burocracia para, a partir daí, poderem prestar contas à população sobre o exercício de seus mandatos. Para isso, o presidente e o gabinete precisam de mecanismos capazes de tomar as contas da burocracia, ou seja, controlar seu desempenho. Essa delegação do presidente para a burocracia é monitorada através dos mecanismos de controle entre políticos e burocratas: nomeação, orçamento, legislação, monitoramento. As principais características desses mecanismos de controle no Brasil são:

v sua concentração no Executivo, em detrimento do Legislativo, e

v a influência da forma de construção da coalizão e do gabinete de governo sobre o funcionamento desses mecanismos de controle.

Vejamos como essas características se apresentam e conformam a nomeação, o orçamento, a legislação e o monitoramento, vistos aqui como mecanismos de controle dos políticos sobre os burocratas.

$\mathrm{O}$ presidente tem o poder de nomear milhares de cargos e funções de confiança, e apenas um número extremamente reduzido deles deve ser ratificado pelo Congresso. Existem quase 70 mil cargos e funções de livre provimento do presidente (Brasil, 2005). As nomeações do presidente que devem ser aprovadas pelo Senado não chegam a uma centena de cargos, apesar de serem cargos de alta relevância, como os de ministros do Supremo Tribunal Federal e dos Tribunais Superiores, ministros do Tribunal de Contas da União, de procurador-geral da República e de presidente e diretores do Banco Central, entre outros (CF, art. 52).

Há um grande número de cargos de livre nomeação, caracterizando uma enorme abertura da burocracia para entradas laterais (em oposição à entrada via concurso e à progressão hierárquica), o que, por sua vez, caracteriza um relativo enfraquecimento da entrada por mérito e da progressão hierárquica com base na carreira. Por outro lado, o Congresso tem poder de aprovar algumas nomeações feitas pelo Executivo para cargos muito importantes, mas esse poder tem sido pouco utilizado, pois há indicações de que a sabatina é 
ritualística (Anastasia, 1999). As nomeações são feitas com base na lógica da formação da coalizão de governo, ou seja, com base nos mesmos critérios das negociações entre Planalto e os partidos e as lideranças regionais quanto à formação da coalizão de apoio ao governo no Congresso. Os controles são feitos, basicamente, de forma informal e pessoal, já que não há mecanismos formais de clearence, e os cargos e as relações pessoais entre os nomeados estruturam a atuação da burocracia (Olivieri, 2007).

Ao repartir o poder entre os aliados da coalizão de governo basicamente preenchendo os postos de direção da burocracia com indicações dos partidos da coalizão, o presidente passa a precisar manter controle sobre a atuação dessa burocracia. Duas características da política e da administração pública brasileira reforçam essa necessidade: os políticos almejam posições no Executivo para se promover politicamente (pois, o poder sobre a elaboração e a execução orçamentárias está no Executivo e não no Legislativo) e a administração pública brasileira é muito aberta (há poucas carreiras estruturadas e muitos cargos de livre nomeação ou de entrada lateral). Ou seja, não só há muitos cargos a serem ocupados, como eles adquirem um peso político muito grande na carreira dos políticos, devido ao tipo de distribuição de poderes entre Executivo e Legislativo.

A repartição de poder e de cargos entre os aliados do governo na coalizão envolve, além de acordos partidários, relações federativas em dois níveis: os cargos de direção da burocracia federal são distribuídos conforme clivagens partidárias e regionais, ou seja, essa distribuição tem de passar por acordos partidários e intrafederativos, e, em outro nível, o formato atual da federação gera uma relação entre governo federal e governos municipais esquizofrênica: os municípios e os estados são autônomos política, administrativa e financeiramente, mas, em sua maioria, dependem, na prática, da transferência de verbas federais e da organização das políticas públicas pelo governo federal (por causa da repartição de competências) para conseguirem cumprir suas obrigações constitucionais (Abrucio, 2005).

Assim como sobre a nomeação de milhares de cargos, o presidente também detém a iniciativa da lei orçamentária, controlando a liberação das verbas através do contingenciamento dos recursos. O Executivo concentra grandes poderes, pois tem "a faca e o queijo na mão", uma vez que a iniciativa da lei orçamentária é exclusiva do presidente e o orçamento é autorizativo e não mandatório. Com tantos poderes sobre a elaboração do orçamento e sobre sua implementação, o presidente exerce enorme controle sobre a liberação das verbas orçamentárias, executando o que foi aprovado no Congresso conforme suas prioridades, praticamente sem prestar contas a ninguém. Sabe-se muito pouco 
sobre a negociação para a liberação das previsões orçamentárias, bem como sobre a negociação das emendas parlamentares ao orçamento - apenas que as emendas individuais são pouco relevantes, tanto em número quanto em valores monetários no total de emendas (Figueiredo e Limongi, 2002). O noticiário político cotidiano é pródigo em apontar acordos que envolvem trocas entre votos no Congresso e liberação de verbas para emendas parlamentares.

A direção da administração pública federal é competência privativa do presidente (CF, art. 84). Isso significa, entre outros poderes, o de reorganizar a administração pública por decreto, ou seja, sem a influência formal do Congresso, quando isso não implicar aumento de despesa nem criação ou extinção de órgãos públicos (CF, art. 84), além da iniciativa legislativa exclusiva quanto à criação de cargos e funções e à criação e extinção de ministérios e órgãos públicos (CF, art. 61).

O controle dos políticos sobre a burocracia também se exerce através da legislação, pela qual se definem os rumos das políticas públicas a serem executadas pela burocracia. Esse poder também é concentrado no Executivo brasileiro, que detém grande poder de iniciativa legislativa, como já vimos, além do poder de decreto (emitir decretos com força de lei: as medidas provisórias). Sabe-se que a negociação em torno da aprovação das leis é feita preponderantemente caso a caso, ou seja, não há acordos prévios e amplos sobre uma agenda mínima a ser implementada pelo governo e por sua coalizão, de tal forma que o Executivo tem de negociar constantemente com sua base de apoio parlamentar. Já se conhecem os efeitos das prerrogativas do Executivo (poder de agenda, poder de decreto) sobre essa negociação com o Congresso. Todavia, esses poderes não são suficientes para uma completa submissão do Congresso ao Executivo, ou seja, há margem de negociação entre presidente e coalizão e dentro da coalizão (entre líderes partidários e seus liderados).

Quanto ao Legislativo, a questão é sua aparente apatia diante dessa concentração de poderes do Executivo, que se reflete inclusive na não utilização dos recursos à disposição do parlamento para controlar as políticas públicas (corpo técnico de assessores parlamentares, poderes constitucionais, órgão de apoio forte e poderoso - o TCU). O controle rotineiro e direto do Congresso e suas comissões sobre o Executivo é fraco e pouco eficaz, apesar do aparato legal, informacional e organizacional à disposição dos congressistas. Concomitantemente a essa fraqueza, entretanto, o Congresso exerce um controle indireto muito importante, através das CPIs, ao prover informações para a sociedade (Figueiredo, 2003).

O monitoramento sobre a execução das políticas públicas no âmbito do Poder Executivo também é atribuição do presidente, mas ela é compartilhada 
com o Congresso, ao qual cabe monitorar a atuação do Executivo através do Tribunal de Contas da União (TCU). Esse é um tema sobre o qual já há alguns trabalhos, como o de Speck (2000) sobre o TCU, que analisa seu papel como órgão de controle entre os Poderes, e o desta autora sobre o controle interno, que analisa especificamente o mecanismo de controle político sobre a burocracia através do estudo da Secretaria Federal de Controle Interno (SFC), que é um órgão do Executivo com atribuição de monitorar o desempenho e a legalidade da atuação da burocracia federal. O significado político do controle interno é controle político via instrumentos burocráticos não apenas sobre a burocracia, mas também sobre a coalizão de governo. Os mecanismos de monitoramento sobre as políticas públicas federais e sobre a atuação da burocracia federal na implementação das políticas federais nos estados e nos municípios acabam "cruzando" com os acordos partidários e regionais, na medida em que esses acordos informaram a nomeação de muitos dos dirigentes dessa burocracia, e na medida em que os prefeitos acabam se tornando responsáveis pela execução de muitas políticas públicas federais implementadas descentralizadamente através de transferências voluntárias do governo federal aos governos subnacionais. Ao fiscalizar as políticas públicas federais implementadas nos municípios, o governo federal tem um instrumento para controlar políticos de outras esferas da União sob uma justificativa formal e impessoal (Olivieri, 2008).

Esta análise incipiente dos mecanismos de controle político sobre a burocracia apresenta muito mais problemas e agendas de pesquisa do que propriamente respostas à nossa questão sobre como se constroem controles políticos democráticos sobre a burocracia. Entender a resposta da burocracia aos diferentes instrumentos de controle político (monitoramento, nomeação, controle orçamentário e legislação) demanda, em primeiro lugar, analisar esses processos como instrumentos de controle da burocracia (e uma das contribuições deste trabalho é nesse sentido) e, em segundo lugar, compreender a resposta da burocracia a eles.

A par disso, é preciso considerar o funcionamento do sistema político. Em nosso caso, o presidencialismo de coalizão acarreta uma enorme dispersão do poder de nomeação do presidente entre os líderes dos partidos da coalizão de governo. Embora a nomeação para milhares de cargos na administração federal seja prerrogativa exclusiva do presidente, sabemos que ele delega esse poder aos membros da coalizão. Sendo o poder de nomeação um dos principais instrumentos do presidente para controlar a burocracia, a questão é: como o presidente consegue manter esse controle? Sabemos que o presidente não perde todo o seu poder com as concessões que faz em nome da manutenção da coa- 
lizão no Congresso, uma vez que ele mantém estrita supervisão sobre os critérios de nomeação adotados pelos aliados e sobre a nomeação de cargos-chave (como os secretários executivos, no governo FHC) (Loureiro e Abrucio, 1999). Mas desconhecemos por completo como o presidente usa os demais poderes de orçamento, de reorganização administrativa e de legislação para dirigir a burocracia, como eles se relacionam entre si, e qual o papel que o Congresso exerce, se exerce algum, no controle político da burocracia. Sabemos que o monitoramento, através do controle interno, é um dos mecanismos que pode ser usado pelo presidente (Olivieri, 2008), mas ainda faltam muitos estudos para podermos construir generalizações e, quem sabe, uma teoria da burocracia.

\section{Referências}

ABERBACH, Joel D. Keeping a watchful eye: the politics os congressional oversight. Washington: The Brookings Institution, 1990.

ABRUCIO, Fernando Luiz. A coordenação federativa no Brasil: a experiência do período FHC e os desafios do governo Lula. Revista de Sociologia e Política, n. 24, p. 41-67, 2005.

ANASTASIA, Fátima (1999). Responsabilização por controle parlamentar. In: ENCONTRO ANUAL DA ANPOCS, XXII, Caxambu, 1999.

BENDIX, Reinhard. Weber, um perfil intelectual. Brasília: Editora da UnB, 1986.

BRASIL (2005). Ministério do Planejamento, Orçamento e Gestão. Secretaria de Recursos Humanos. Boletim Estatístico de Pessoal. Brasília: MPOG, fev. 2005. v. 106.

CAMPANTE, Rubens Goyatá. O patrimonialismo em Faoro e Weber e a sociologia brasileira. Dados, Rio de Janeiro, v. 46, n. 1, p. 153-193, 2003.

DIVINE, Donna Robinson. A political theory of bureaucracy. Public Administration, v. 57, n. 2, 1979.

EISNER, Marc Allen; MEIER, Kenneth J. Presidential control versus bureaucratic power: explaining the Reagan revolution in antitrust. American Journal of Political Science, v. 34, n. 1, p. 269-287, Feb. 1990.

FIGUEIREDO, Argelina. The role of Congress as an agency of horizontal accountability: lessons form the Brazilian experience. In: MAINWARING, Scott; WELNA, Christopher. Democratic accountability in Latin América. New York: Oxford University Press, 2003.

FIGUEIREDO, Argelina; LIMONGI, Fernando. Incentivos eleitorais, partidos e política orçamentária. Dados, Rio de Janeiro, v. 45, n. 2, p. 303-344, 2002. 
FREUND, Julien. Sociologia de Max Weber. 5. ed. Rio de Janeiro: Forense Universitária, 2003.

LAMOUNIER, Bolívar. Brazil: toward parlamentarism? In: LINZ, J.J.; VALENZUELA, A. (Comp.). The failure of presidential democracy: the case of Latin America. Baltimore: The Johns Hopkins University Press, 1994.

LIMONGI, Fernando; FIGUEIREDO, Argelina. Bases institucionais do presidencialismo de coalizão. Lua Nova, São Paulo, n. 44, p. 81-106, 1998.

LONG, Norton E. Bureaucracy and Constitutionalism. The American Political Science Review, v. 46, n. 3, Sept. 1952.

LOUREIRO, Maria Rita; ABRUCIO, Fernando Luiz. Política e burocracia no presidencialismo brasileiro: o papel do Ministério da Fazenda no primeiro governo Fernando Henrique Cardoso. Revista Brasileira de Ciências Sociais, v. 14, n. 41, p. 69-89, out. 1999.

LOUREIRO, Maria Rita; OLIVIERI, Cecília; MARTES, Ana Cristina Braga. Burocratas, partidos e grupos de interesse: o debate sobre política e burocracia no Brasil. In: LOUREIRO, Maria Rita; ABRUCIO, Fernando Luiz; PACHECO, Regina. Burocracia e Política: desafios para o Estado democrático no século XXI. Rio de Janeiro: Editora FGV, 2010.

MACKENZIE, G. Calvin; SHOGAN, R. Obstacle course: the Report of the twentieth century fund task force on the presidential appointment process. New York: The Twentieth Century Fund Press, 1996.

MAINWARING, Scott. Multipartism, robust federalism and presidentialism in Brazil. In: MAINWARING, S.; SHUGART, M.S. (Ed.). Presidentialism and democracy in Latin America. Cambridge: Cambridge University Press, 1997.

MAINWARING, Scott; WELNA, Christopher. Democratic accountability in Latin América. New York: Oxford University Press, 2003.

MARQUES, Eduardo. Notas críticas à literatura sobre Estado, políticas estatais e atores políticos,. BIB - Revista Brasileira de Informação Bibliográfica em Ciências Sociais, n. 43, 1997.

MARTINS, Carlos Estevam. Governabilidade e controles. Revista de Administração Pública, Rio de Janeiro, v. 23, n. 1, 1989.

McCUBBINS, Mathew D.; NOLL, Roger G.; WEINGAST, Barry R. Administrative procedures as instruments of political control. Journal of Law, Economics and Organization, v. 3, n. 2, p. 243-277, Fall 1987.

MEDEIROS, Paulo Henrique R.; GUIMARÃES, Tomás de Aquino. O estágio do governo eletrônico no Brasil em relação ao contexto mundial. Revista do Serviço Público, n. 1 e 2, jan./jul. 2004. 
NUNES, Edson. A gramática política do Brasil: clientelismo e insulamento burocrático. 2. ed. Rio de Janeiro: Jorge Zahar; Brasília: Enap, 1999.

OLIVIERI, Cecília. A lógica política do controle interno: o monitoramento das políticas públicas no presidencialismo brasileiro. São Paulo: Annablume, 2010.

OLIVIERI, Cecília. Política, burocracia e redes sociais: as nomeações para o alto escalão do Banco Central do Brasil. Revista de Sociologia Política, n. 29, p. 147-168, 2007.

OLIVIERI, Cecília. Política e burocracia no Brasil: o controle sobre a execução das políticas públicas. Tese (doutorado) - Eaesp, Fundação Getulio Vargas, São Paulo, 2008.

PALERMO, Vicente. Como se governa o Brasil? O debate sobre instituições políticas e gestão de governo. Dados, Rio de Janeiro, v. 43, n. 3, p. 147-168, 2000.

POLLITT, Christopher; BOUCKAERT, Geert. Avaliando reformas da gestão pública: uma perspectiva internacional. Revista do Serviço Público, n. 3, jul./set. 2002.

SANCHEZ, Oscar Adolfo. Os controles internos da administração pública: a e-governança e a construção de controles no governo do estado de São Paulo. Tese (doutorado) - Faculdade de Filosofia, Letras e Ciências Humanas, Departamento de Ciência Política, USP, 2005.

SPECK, Bruno W. Inovação e rotina no TCU: o papel da instituição superior de controle financeiro no sistema político-administrativo do Brasil. Rio de Janeiro: Fundação Konrad Adenauer, 2000.

WEBER, Max. A política como vocação. In: WEBER, Max. Ensaios de sociologia. Org. por H.H. Gerth e C. Wright Mills. Rio de Janeiro: Guanabara, 1982.

WEBER, Max. Parlamento e governo na Alemanha reordenada: crítica política da burocracia e da natureza dos partidos. Petrópolis: Vozes, 1993.

WEBER, Max. Economia e sociedade: fundamentos de sociologia compreensiva. Brasília, DF: Editora UnB, 1999. v. 2.

WILSON, Woodrow. The study of administration. Political Science Quaterly, v. 2, n. 2, June 1887.

WOOD, B. Dan; WATERMAN, Richard W. The dynamics of political control of the bureaucracy. The American Political Science Review, v. 85, n. 3, p. 801-828, Sept. 1991.

WOOD, B. Dan; WATERMAN, Richard W. Bureaucratic dynamics: the role of bureaucracy in a democraacy. Boulder: Westview Press, 1994. 